\title{
La necesidad de una doctrina sobrenatural en Duns Scoto como reacción contra el aristotelismo ${ }^{1}$
}

\section{The Need for a Supernatural Doctrine in Duns Scotus as a Reaction against Aristotelianism}

\author{
Hernán Guerrero Troncoso \\ Universidad Católica del Maule
}

Recibido: 31/08/2015

Aceptado: 11/04/2016

\section{Resumen}

Este artículo pretende indicar, mediante un examen de la cuestión sobre la necesidad de la Revelación, en qué sentido se debe entender la posición de Duns Scoto en relación con la validez de la doctrina revelada ante la razón natural, cuya figura principal era Aristóteles. Dado que el Doctor Sutil opone el conocimiento natural al sobrenatural, en este trabajo se determina asimismo cómo se debe asumir el significado de "naturaleza" y "natural" en relación con el conocimiento, y en qué sentido un conocimiento se puede considerar sobrenatural. En la parte final, se presentan algunas reflexiones relativas a la distancia que Scoto y el pensamiento cristiano en general mantiene con Aristóteles, y con una filosofía que ignora o prescinde de la Revelación.

Palabras clave: Naturaleza, Interpretación, Pensamiento Escolástico, Revelación, Razón Natural.

\begin{abstract}
The intention of this paper is to suggest, through an examination of the question about the need for Revelation, the sense in which one must understand Duns Scotus' position regarding the validity of a revealed doctrine confronted against natural reason, whose main figure was Aristotle. Since the Subtle Doctor opposes natural

\footnotetext{
${ }^{1}$ El presente artículo constituye una versión revisada de la conferencia "Impossibile est hic contra Aristotelem uti ratione naturali. La necesidad de una doctrina sobrenatural en Duns Scoto como reacción al aristotelismo", presentada en el congreso "Historia de la filosofía como historia del antiaristotelismo", 12-14 de agosto, 2014, Universidad Diego Portales (Santiago de Chile), organizado por el prof. Dr. Miguel Saralegui Benito.
} 
to supernatural knowledge, this work also determines how one must assume the meaning of "nature" and "natural" with regard to knowledge, and in which sense a given knowledge can be considered supernatural. In the final part, some reflections concerning the distance Scotus and Christian thought in general keeps with Aristotle, and with a philosophy that ignores or disregards the Revelation.

Keywords: Nature, Interpretation, Scholastic Thought, Revelation, Natural Reason.

\section{Sumario}

1. Introducción

2. El fundamento de la controversia entre filósofos y teólogos sobre la validez de la Revelación

2.1. Los argumentos de los filósofos y la reafirmación de la perfección de la naturaleza en sí misma

2.2. Las objeciones teológicas y la afirmación general de la necesidad de una doctrina revelada

2.3. La objeción en torno al conocimiento racional que se puede tener de las sustancias separadas

3. La distinción escotista entre 'natural' y 'naturaleza' y el sentido en que se debe entender la necesidad de una doctrina revelada

3.1. Los sentidos de lo natural, a partir de sus nociones opuestas

3.2. Los sentidos de naturaleza y la relación del ámbito de las criaturas con Dios

4. A modo de conclusión. Los límites de una doctrina sobrenatural y del intelecto humano en esta vida

5. Referencias bibliográficas

5.1. Fuentes

5.2. Estudios

\section{Introducción}

Que sean unos versos de Dante los que nos guíen en este trabajo:

Poi che inalzai un poco più le ciglia, vidi 'l maestro di color che sanno seder tra filosofica famiglia.

Tutti lo miran, tutti onor li fanno: 
quivi vid'ïo Socrate e Platone,

che innanzi alli altri più presso li stanno ${ }^{2}$.

Es tal la importancia de quien está sentado en medio de los filósofos, que el poeta florentino no necesita mencionar su nombre: se puede conformar con indicar simplemente que se trata del "maestro de aquellos que saben" y que es honrado por todos, especialmente por quienes "le están más cerca", nada menos que Sócrates y Platón. De hecho, ni los teólogos ni los filósofos de la Escolástica debían llamarlo por su nombre, sino que hablaban del Filósofo. Solo el comienzo de una de sus sentencias bastaba para comprender el contexto y el alcance del argumento que se presentaba. Los maestros más importantes de las Facultades de Teología del siglo XIII se dedicaron a comentar sus obras, hicieron propio su pensamiento y lo replantearon en el contexto especulativo cristiano, sirviéndose de él para poner de manifiesto la validez de la doctrina cristiana según los términos de la razón natural ${ }^{3}$. Su doctrina llegó incluso a constituir el punto de partida para demostrar la existencia de Dios de manera racional, como ocurre con las famosas cinco vías de santo Tomás ${ }^{4}$. ¿Es adecuado, entonces, sostener que en la Escolástica se dio una reacción contra Aristóteles y el aristotelismo?

Pues bien, las condenas que tuvieron lugar en París durante el siglo XIII, y que afectaron a maestros de la Facultad de Artes o a doctrinas que no eran conformes o que eran contrarias a los dogmas de fe, son una muestra de la influencia que ejerció el aristotelismo sobre el pensamiento de esa época. Su influencia fue tan grande, que hizo necesaria más de una censura por parte de las autoridades eclesiásticas, las que consistieron sobre todo en la prohibición de que se enseñaran posiciones basadas en Aristóteles o en sus comentaristas que no fueran conformes a la doctrina cristiana ${ }^{5}$. Sin embargo, a pesar de dichas condenas, el Filósofo continuó siendo estudiado y comentado, y sus doctrinas siguieron constituyendo el trasfondo especulativo de las

\footnotetext{
${ }^{2}$ Dante Alighieri. Commedia. Inferno IV, 130-135. Revisione del testo e commento di G. Inglese. Carocci, Roma 2007, p. 79.

${ }^{3}$ Cf. por ejemplo s. Tomás de Aquino, Summa contra gentiles I, c. 1, en S. Thomae de Aquino Opera omnia, iussu Leonis XIII PM edita, cura et studio Fratrum Praedicatorum, vol. XIII, Garroni, Roma 1918, p. 1ab. [Después de la primera cita, en el caso de colecciones de obras completas, las fuentes se citarán por número de volumen y página. Para mayores detalles sobre la edición, se puede consultar la bibliografía al final del artículo. En el caso del Aristoteles latinus, se usará la abreviatura AL y el número de volumen].

${ }^{4}$ Cf. s. Tomás de Aquino, Summa theologiae I, q. 2 a. 3 in corp., IV 31ab-32ab.

${ }^{5}$ Cf. al respecto Piché, D. La condamnation parisienne de 1277, Vrin, Paris 1999; Van Steenberghen, F. Aristotle in the West. The Origins of Latin Aristotelianism, translated by L. Johnston. E. Nauwelarts, Louvain 1955, pp. 59-88; pp. 230-238; Aertsen, J.A. - Emery, K. - Speer, A. (eds.) Nach der Verurteilung von 1277: Philosophie und Theologie an der Universität von Paris im letzten Viertel des 13. Jahrhunderts. Studien und Texte, Miscellanea Mediaevalia 28, De Gruyter, Berlin - New York 2001.
} 
reflexiones teológicas de la época. Solo en el caso de Duns Scoto, casi la totalidad de sus escritos filosóficos consisten en cuestiones sobre textos de Aristóteles ${ }^{6}$, mientras que la autoridad del Filósofo es citada recurrentemente en sus escritos teológicos, para ilustrar desde un punto de vista racional asuntos propios de la fe. Aun así, por mucho que el Doctor Sutil haya conocido el pensamiento de Aristóteles, que haya seguido sus posiciones metafísicas fundamentales y que haya usado la lógica con gran maestría, no se puede decir que sea un aristotélico puro, ni que haya tenido intención de serlo del todo, ya que uno de los fundamentos últimos del pensamiento del maestro franciscano, como él mismo reconoce, lo constituye la doctrina católica ${ }^{7}$.

Con el fin de determinar dónde radica para Scoto la diferencia entre el conocimiento filosófico y el teológico, el presente trabajo interpretará la cuestión que abre su obra teológica principal, conocida como Ordinatio, en la que se pregunta si es necesario que el hombre se inspire en esta vida por una doctrina sobrenatural para alcanzar la salvación, la que no podría se alcanzar mediante la sola luz natural del intelecto ${ }^{8}$. El maestro franciscano no lleva a cabo aquí un examen de ambas ciencias en un sentido abstracto -como una especie de "contienda de las Facultades"-, sino que como una discusión entre filósofos y teólogos. En este sentido, opone algunos argumentos de los filósofos -quienes afirmarían que el conocimiento que el hombre adquiere de manera natural es suficiente para alcanzar la salvación- a argumentos de los teólogos, en los que se discute la validez de lo que sostienen los filósofos y se afirma la necesidad de una doctrina sobrenatural. La respuesta de Scoto intenta demostrar la necesidad de la Revelación, y para ello presenta, junto a la oposición aristotélica entre natural, violento y neutro, una oposición entre natural y sobrenatural, con lo que se puede advertir que es posible proponer un acercamiento entre la razón natural y la doctrina revelada, a pesar de que ello no implica que esta última sea capaz, por la sola fuerza de sus argumentos y sin la fe, de demostrar a la razón natural la verdad de sus afirmaciones.

\footnotetext{
${ }^{6}$ Los cinco volúmenes de sus obras filosóficas contienen cuestiones sobre las Categorías, el Perihermeneias -dos series de cuestiones-, las Refutaciones sofisticas, la Metafísica -hasta el libro IX-y el De anima. Solo las cuestiones sobre la Isagoge de Porfirio y los Theoremata no tienen un texto de Aristóteles como base.

${ }^{7}$ Cf. b. Juan Duns Scoto, Ordinatio I, d. 5 n. 26, en B. Ioannis Duns Scoti Opera omnia, studio et cura Commissionis Scotisticae. vol. IV, Typis Polyglottis Vaticanis, Civitas Vaticana 1956, p. 25: "Non autem nullam [Petrus Lombardus] habet pro se auctoritatem, sed habet illam universalis Ecclesiae in capitulo praeallegato, quae maxima est, quia diciti Augustinus Contra epistolam Fundamenti: 'Evangelio non crederem nisi Ecclesiae crederem catholicae",; Guerrero Troncoso, H. "La questione sul fondamento dell'autorità. Duns Scoto e Giovanni Damasceno sulla processione dello Spirito Santo", en Fides Quaerens 3 (2012), pp. 117-151; íd., "Si duo sapientes, unius veritatis et non propriae dictionis amatores... Duns Scoto e la dottrina di s. Giovanni Damasceno sulla processione dello Spirito Santo (I)", en Porphyra $13^{1}$ (2009), pp. 18-39.

${ }^{8}$ Cf. Duns Scoto, Ordinatio prólogo, p. 1 q. un., I 1-59; Lectura prólogo, p. 1 q. un., XVI 1-29; González Ginocchio, D. Ser e infinito en Duns Scoto, Eunsa, Pamplona 2013, pp. 37-80.
} 
La presente investigación se divide en tres partes. En la primera, se exponen los argumentos de filósofos y teólogos, y se examina con mayor detención el tercero de los argumentos de estos últimos. En la segunda, se verá en qué consiste la diferencia entre natural y sobrenatural según Scoto, que constituye el fundamento sobre el cual se puede afirmar la necesidad de la doctrina revelada. Finalmente, en la tercera y última parte, se examinarán dos parágrafos que el Doctor Sutil añadió en su revisión de la Ordinatio, en especial uno en el que reconoce los límites de la validez de los argumentos teológicos, con lo cual en cierta medida comenta su respuesta a la cuestión? De esta manera, se intentará vislumbrar cuál es la posición de nuestro Doctor en vista de la autoridad y la doctrina de Aristóteles, para así poder determinar hasta qué punto se puede considerar aristotélico, o si en el fondo en su doctrina se puede advertir una reacción contra el aristotelismo, y en qué consistiría dicha animadversión.

\section{El fundamento de la controversia entre filósofos y teólogos sobre la validez de la Revelación}

En su examen sobre la necesidad de una doctrina revelada, se podría pensar que Scoto reduce todo el problema a una controversia doctrinal entre filósofos y teólogos en torno a los límites del conocimiento que el hombre es capaz de alcanzar en esta vida de modo natural. Sin embargo, como dice Scoto, dicha controversia debe ser entendida en el sentido de que

Los filósofos afirman el carácter perfecto de la naturaleza -y con ello la suficiencia del conocimiento natural-, y niegan que haya una perfección sobrenatural. Por el contrario, los teólogos reconocen el carácter carente de la naturaleza, la necesidad de la gracia y la perfección sobrenatural ${ }^{10}$.

\footnotetext{
${ }^{9}$ Esta distinción sigue el método de Giorgio Pini en sus trabajos sobre la analogía en Scoto, donde trata por separado la sección original del texto y las adiciones que agregó con posterioridad nuestro Doctor, para que así sea más clara la función que cumplen las adiciones, si es que corrigen, comentan o reflexionan sobre el texto principal. Cf. Pini, G. Scoto e l'analogia. Logica e metafisica nei commenti aristotelici, Scuola Normale Superiore, Pisa 2002, pp. 85-141; “Univocity in Scotus' Quaestiones super Metaphysicam. The Solution to a Riddle", en Medioevo 30 (2005), pp. 69-110.

${ }^{10}$ Cf. Duns Scoto, Ordinatio prólogo, p. 1 q. un. n. 5, I 4; Lectura prólogo, p. 1 q. un n. 5, XVI 2: "Omnes catholici conveniunt in hoc quod sit aliqua cognitio supernaturalis nobis in via necessaria; sed controversia est inter theologos et philosophos". Todas las traducciones son nuestras. En castellano actualmente hay dos traducciones del prólogo de la Ordinatio: Dios uno y trino. Versión de los padres B. Aperribay et. al, introducción general de M. Oromí, Biblioteca de Autores Cristianos, Madrid 1960 (actualizada por el volumen Filosofía y teología, Dios y el hombre, presentación, introducción y edición de J. A. Merino, Biblioteca de Autores Cristianos, Madrid 2011. Contiene también el tratado De primo principio), e Guzmán Manzano, I. Fe y razón en Juan Duns Escoto. Prólogo al Libro de las Sentencias de P. Lombardo. Edición bilingüe y versión española del Prólogo, editada por J. Ortín García y F. Martínez Fresneda, Publicaciones del Instituto Teológico de Murcia OFM - Editorial Espigas, Murcia 2009.
} 
Así, con esta afirmación se pone de manifiesto que la solución del problema no pasa por una demostración de la validez de la Revelación a expensas del conocimiento natural, sino que más bien hace ver que la determinación de los límites de dicho conocimiento puede servir como punto de partida para una discusión sobre la validez de la Revelación, ya que el fundamento de la controversia entre filósofos y teólogos radicaría en último término en la manera en que cada uno de ellos concibe la naturaleza y lo que tiene lugar naturalmente. Por ende, es a partir de una elucidación de los sentidos que poseen las nociones de 'naturaleza' y 'natural' que se podrá afirmar la validez de un conocimiento y de una doctrina sobrenaturales. Antes de proceder con dicho examen, es necesario determinar los términos en que filósofos y teólogos entienden el conocimiento natural y sus límites.

\subsection{Los argumentos de los filósofos y la reafirmación de la perfección de la natura- leza en sí misma}

El maestro franciscano resume la posición de los filósofos diciendo que para ellos todo el conocimiento necesario para el hombre en esta vida se puede adquirir mediante la acción de las causas naturales, sin que sea necesario un conocimiento que las supere ${ }^{11}$. Según Scoto, esto se puede demostrar a partir de las condiciones del conocimiento humano, de la división de los hábitos en especulativos y prácticos, y de la relación entre los primeros principios del conocimiento y las conclusiones que se pueden desprender de ellos.

Así, el primer argumento afirma que basta con la simple reunión entre intelecto agente y paciente para que tenga lugar el conocimiento, y dicha reunión tiene siempre lugar, si algo no lo impide. El fundamento de esta afirmación se encuentra en el hecho de que si algo que es naturalmente activo llega a estar en presencia de algo que es naturalmente pasivo, y no hay nada que impida su reunión, la acción que debería tener lugar a partir de ellos ocurre de manera necesaria ${ }^{12}$. Según este principio, y teniendo en cuenta que el intelecto agente es el principio activo de todo lo inteligible y que el intelecto paciente es capaz de recibir toda intelección posible, y dado que ambos se encuentran naturalmente en el alma, se desprende que todo acto intelectivo debería tener lugar de manera natural con respecto a todo lo que se puede dar a conocer. Scoto confirma esta afirmación diciendo que, tal como a toda potencia pasiva natural le corresponde una potencia activa natural que perfeccione su capacidad -de no ser así, su presencia en la naturaleza sería en

\footnotetext{
${ }^{11}$ Cf. Duns Scoto, Ordinatio prólogo, n. 5, I 5.

${ }^{12}$ Cf. Aristóteles, Metaphysica IX c. 5, 1048a 6-8. Recensio et translatio Guillelmi de Moerbeka. Ed. G. Vuillemin-Diem. Aristoteles Latinus XXV 3.2, Brill, Leiden - New York - Köln 1995, p. 184: "Tales quidem potentiae [scil. irrationabiles] necessae, quando ut possint passivum et activum appropinquant, hoc quidem facere illud vero pati".
} 
vano, ya que nunca podría ser actualmente-, si no hubiera un agente natural capaz de llevar al intelecto paciente a conocer, sería una potencia en vano. De hecho, el deseo que posee el intelecto paciente por conocer todo lo que se da a conocer indica que puede ser consumada por todo conocimiento, y por ende debe ser capaz de recibir todo conocimiento naturalmente ${ }^{13}$.

El segundo argumento sostiene que de la división aristotélica de los hábitos del alma intelectiva en especulativos y prácticos $-\mathrm{y}$ de su subdivisión en ciencia física, matemática y metafísica, y en hábitos activos y productivos, respectivamente- se puede concluir que no habría ningún otro hábito apartes de ellos, ya que en ambos casos los hábitos mencionados abarcan el conocimiento de todo lo que es, tanto del ser en cuanto tal como de sus partes. Por lo tanto, si el conocimiento práctico que se puede adquirir en esta vida de manera natural es suficiente para que se perfeccione el intelecto práctico, el conocimiento especulativo también es suficiente para consumar el intelecto especulativo ${ }^{14}$.

Por último, el tercer argumento sostiene que quien conoce los principios de modo natural, puede conocer de igual manera las conclusiones contenidas en ellos. En efecto, el conocimiento de las conclusiones no dependería más que del hecho de haber entendido los principios y de la deducción que se lleva a cabo a partir de ellos, de acuerdo con la definición aristotélica de conocimiento ${ }^{15}$. Luego, dado que la verdad del proceso deductivo -ya que se trata de un procedimiento que el intelecto realiza por sí solo mediante el silogismo- sería evidente por sí sola, resulta que, si los primeros principios se pueden entender naturalmente, el intelecto contaría de manera natural con todo lo necesario para conocer las conclusiones que están incluidas en dichos principios. Puesto que esos principios, como la noción de ser y de cosa -en los que se incluyen todas las conclusiones posibles, y que por eso son comunes a todo lo que es, de tal modo que están presentes en todo concepto particular- se entienden de manera natural, se puede afirmar que el hombre es capaz de conocer naturalmente en esta vida todas las conclusiones incluidas en dichos principios, y así puede conocer todo lo que es ${ }^{16}$.

\footnotetext{
${ }^{13}$ Cf. Duns Scoto, Ordinatio prólogo, n. 6-7, I 5-6.

${ }^{14}$ Cf. Duns Scoto, Ordinatio prólogo, n. 8, I 6.

${ }^{15}$ Cf. Aristóteles, Analytica posteriora I c. 2, 71b 9-12, AL IV ${ }^{1}$ 5: "Et putamus quod nos scimus unamquamque rerum scientia vera, non secundum modum sophistarum qui est per viam accidentis, quando scimus causam facientem esse eius, et scimus quod ipsa est causa eius et quod non est possibile ut sit sine ipsa"; Duns Scoto, Ordinatio prólogo, n. 208, I 141: "Scientia stricte sumpta quattuor includit, videlicet: quod sit cognitio certa, absque deceptione et dubitatione; secundo, quod sit de cognito necessario; tertio, quod sit causata a causa evidente intellectui; quarto, quod sit applicata ad cognitum per syllogismum vel discursum syllogisticum".

${ }^{16}$ Cf. Duns Scoto, Ordinatio prólogo, n. 9-11, I 7-8.
} 


\subsection{Las objeciones teológicas y la afirmación general de la necesidad de una doc- trina revelada}

La discusión continúa con cinco objeciones teológicas a la posición de los filósofos. De dichos argumentos, Scoto sostiene que los tres primeros son los más convincentes contra los filósofos, ya que considera que los dos últimos no son concluyentes ${ }^{17}$. Asimismo, nuestro Doctor no se limita a exponer dichos argumentos, sino que pone en discusión su validez a través de diversas objeciones, con lo cual se hace cargo y responde a las posibles críticas que puedan suscitar. En esta exposición se omitirá esa parte dialéctica y solo se enunciarán los argumentos, salvo en el caso del tercero, que se presentará con las objeciones y la respuesta del maestro franciscano al final de esta sección ${ }^{18}$.

El primer argumento - que ya había propuesto santo Tomás ${ }^{19}$ - sostiene que todo agente que actúa por conocimiento necesita conocer de manera distinta el fin de su acción, ya que todo aquel que actúa en vista de un fin, lo hace por el deseo de alcanzar dicho fin $^{20}$. En este sentido, ya que tanto un ser que actúa por sí solo de modo natural como quien actúa con conocimiento lo hace en vistas del fin, de acuerdo con Aristóteles ${ }^{21}$, este último agente debe actuar movido por el deseo de alcanzar dicha finalidad. Sin embargo, resulta que en esta vida el hombre no es capaz de alcanzar el conocimiento de su proprio fin por medios naturales, y por lo tanto es necesario que lo adquiera mediante una doctrina sobrenatural. Scoto alude aquí el tono dubitativo que encuentra en Aristóteles cuando afirma que la felicidad humana consiste en el conocimiento de las sustancias separadas, y concluye que el Filósofo, en la medida en que se basa solo en la razón natural, "o bien caerá en error acerca del fin [del hombre] en particular, o bien quedará en la duda" ${ }^{2}$.

\footnotetext{
${ }^{17}$ Esos últimos argumentos son presentados por Enrique de Gante; cf. Enrique de Gante, Summa (quaestiones ordinariae), a. 8 d. 2 in corp., ed. Badius I, f. 64H-I; ibíd., a. 3 q. 4 in corp., ed. G. Wilson, Ancient and Medieval Philosophy series 2, vol. XXI, Leuven University Press, Leuven 2005, pp. 258259.

${ }^{18}$ Una presentación detallada de los argumentos se encuentra en González Ginocchio, Ser e infinito, pp. 54-75.

${ }^{19}$ Cf. s. Tomás de Aquino, S. theol. I, q. 1 a. 1 in corp., IV 6b: "Finem autem oportet esse praecognitum hominibus, qui suas intentiones et actiones debent ordinare in finem. Unde necessarium fuit homini ad salutem, quod ei nota fierent quaedam per revelationem divinam, quae rationem humanam excedunt"; íd., Quaestiones disputatae de veritate, q. 14 a. 10 arg. 3, XXII ${ }^{2} 465$ a.

${ }^{20}$ Cf. Aristóteles, Metaph. II c. 2, 994b 14-16, AL XXV 3.2 46: "Nullus conabitur aliquid facere ad terminum non futurus venire".

${ }^{21}$ Cf. Aristóteles, Physica II c. 5, 196b 17-22, AL VII 68.

${ }^{22}$ Duns Scoto, Ordinatio prólogo, n. 14, I 10; cf. Aristóteles, Ethica Nicomachea I c. 6, 1097b 221098a 20, AL XXVI-3 150-151; ibíd., X c. 7, 1177a 12-b 1, AL XXVI ${ }^{1-3} 358-359$; c. 8, 1178b 7-32, AL $\mathrm{XXVI}^{1-3} 362-363$; c. 9, 1179a 22-32, AL XXVI ${ }^{1-3}$ 364; ibíd., I c. 10, 1099b 11-13, AL XXVI'-3 154: "Si quidem igitur et aliud aliquod deorum est donum hominibus, rationabile et felicitatem, dei datum esse".
} 
Como demostración adicional de este argumento, el Doctor Sutil afirma que, puesto que el fin proprio de una sustancia no se conoce sino a través de la actividad de esta última -mediante la cual queda en evidencia no solo cuál es su fin, sino también que ese fin conviene a dicha sustancia- el hombre no tiene experiencia ni conocimiento en esta vida de que su fin proprio consiste en la visión de las sustancias separadas, y por ende no es capaz de conocer naturalmente de manera distinta que es adecuado a su esencia. Esto es cierto, continua nuestro Doctor, al menos en lo que dice relación con el hecho de que algunas determinaciones de su fin último -en virtud de las cuales el hombre debería buscar dicho fin con un deseo mayor y más ferviente- no pueden ser conocidas de manera distinta por la razón natural, como por ejemplo el hecho de que la visión y el goce puros de Dios constituyen el fin último del hombre. Incluso si se pudiera sostener eso por la sola razón natural, no se puede concluir que dicha visión le corresponde al hombre completo, en cuerpo y alma, a perpetuidad ${ }^{23}$. Por ello, hay ciertas determinaciones del fin último, que llevarían al hombre a buscarlo con mayor ahínco, que la razón natural no es capaz de poner en evidencia, de tal modo que es necesaria una doctrina revelada ${ }^{24}$.

En el segundo argumento, nuestro Doctor sostiene que todo aquel que actúa por conocimiento necesita saber, junto con el fin al que tiende, la manera y la calidad (quomodo et qualiter) en que alcanzará ese fin -para así saber cómo se debe disponer para conseguirlo-, qué se requiere para alcanzarlo -ya que si desconoce algún requisito necesario, puede terminar por no conseguir su objetivo-, y que dichos requisitos bastan para alcanzar dicho fin -en este sentido, por ignorancia podría seguir buscando algo innecesario, y descuidar lo que ya posee y que sí es necesario-. Ninguna de estas tres condiciones, dice Scoto, puede ser conocida por el hombre en esta vida. Así, en lo que respecta a la primera, los cristianos sostienen que la felicidad eterna es algo que Dios concede como un premio, en cuanto que acepta las acciones del hombre como meritorias de la felicidad eterna $-y$ por ende, alcanzar esa felicidad sería más bien algo contingente-, y no porque mediante sus acciones el hombre deba alcanzar necesariamente dicha felicidad. Así, puesto que varios filósofos sostienen que todo emana de Dios de manera necesaria, se puede concluir que la razón natural no es capaz de afirmar por sí sola el carácter contingente de la felicidad eterna, y que el hombre se debe disponer a ese fin en esta vida. Las otras dos condiciones son más evidentes, ya que la razón natural no puede concluir algo que es contingente, como la aceptación de los méritos del hombre por parte de la voluntad divina como dignos de la vida eterna, y que solo eso baste para alcanzar el fin propio del hombre ${ }^{25}$.

\footnotetext{
${ }^{23}$ Cf. Duns Scoto, Ordinatio IV, d. 43 n. 146-150, XIV 42-44.

${ }^{24}$ Cf. Duns Scoto, Ordinatio prólogo, n. 13-16, I 9-11.

${ }^{25}$ Cf. Duns Scoto, Ordinatio prólogo, n. 17-18, I 11-13. Inmediatamente después se encuentran las objeciones (n. 19-27, I 13-16) y las respuestas de Scoto (n. 28-39, I 16-22).
} 
Los últimos dos argumentos -que según nuestro Doctor no son tan concluyentes como los anteriores- fueron tomados de Enrique de Gante. El primero sostiene que todo lo que está ordenado en vistas de un fin para el cual se encuentra indispuesto, necesariamente se debe acercar a él de manera paulatina. Esto ocurre con el hombre, que se encuentra ordenado hacia un fin sobrenatural, pero por sí está indispuesto para él, de tal modo que es necesario que mediante un conocimiento sobrenatural - a pesar de que es imperfecto- se vaya poco a poco encaminando hacia aquel fin. El segundo argumento parte del principio que un agente que se sirve de un instrumento para actuar, no puede llevar a cabo una acción que supere dicho instrumento. Ese sería el caso de la luz del intelecto agente, que constituiría el instrumento del cual se sirve el alma para entender de manera natural en esta vida, y ende el hombre no podría conocer nada que supere dicha luz. Se puede entonces concluir, dado que la luz del intelecto agente se encuentra limitada al conocimiento que se adquiere mediante los sentidos (per viam sensitivam et viam sensuum), que el alma humana en esta vida no es capaz de conocer nada que supere el conocimiento sensible. Sin embargo, como el conocimiento de muchos otros objetos que superan lo sensible es necesario para el hombre en esta vida, un conocimiento sobrenatural sería necesario ${ }^{26}$.

\subsection{La objeción en torno al conocimiento racional que se puede tener de las sustan- cias separadas}

La tercera objeción teológica merece una mayor atención, ya que en ella se aprecia cuál sería para nuestro Doctor el límite de un conocimiento racional de Dios, y en general de las sustancias separadas, y con ello se puede advertir mejor cuál sería el lugar que ocuparía una doctrina revelada y su relación con el conocimiento natural. Este argumento constituye un examen crítico del alcance de la afirmación de Aristóteles, que sostiene que el conocimiento supremo sería el de las sustancias separadas, pues ellas constituyen el género supremo de seres ${ }^{27}$. Scoto distingue dos sentidos en que las sustancias separadas pueden ser conocidas, a saber, atendiendo a aquello que poseen en común con las sustancias sensibles, y a aquello que es proprio de ellas. Este último sería el conocimiento más necesario y el más alto en absoluto para nosotros.

Sin embargo, el maestro franciscano estima que en esta vida el hombre no es capaz de alcanzar un conocimiento de lo que es proprio de las sustancias separadas de modo puramente natural, y presenta dos razones para fundamentar su posición. En primer lugar, si en esta vida hubiera una ciencia capaz de alcanzar dicho conocimiento, dicha ciencia sería la metafísica, pero es evidente que en ella no se encuentra. Más aun, es el mismo Aristóteles quien afirma que el sabio - es decir, aclara nuestro

\footnotetext{
${ }^{26}$ Cf. ibíd., n. 13-54, I 9-32; las objeciones se hallan en n. 50, I 30, y n. 52-53, I 31-32.

${ }^{27}$ Cf. Aristóteles, Metaph. VI c. 1, 1026a 20-33, AL XXV ${ }^{3.2} 127$.
} 
Doctor, el metafísico-, en la medida en que conoce las nociones universales, conoce hasta cierto punto todo lo que es, pero no de modo particular ${ }^{28}$.

Dicha imposibilidad se concluye también a partir de las condiciones del conocimiento científico, es decir, que no se pueden conocer esas propiedades por deducción ni mediante el reconocimiento de su existencia a partir de sus efectos. En el primer caso, el conocimiento deductivo (propter quid) de dichas propiedades tiene lugar en virtud del conocimiento de los sujetos en cuanto tales, dado que solo ellos contienen en su esencia tales propiedades. Las sustancias separadas, sin embargo, no pueden ser conocidas en cuanto tales de manera natural por nosotros en esta vida; por ende, si llegamos a tener algún tipo de conocimiento de ellas, eso será gracias a una doctrina sobrenatural ${ }^{29}$.

El Doctor Sutil tampoco estima que las propiedades de las sustancias separadas se puedan conocer de modo natural en esta vida mediante un reconocimiento de su existencia a partir de sus efectos (demonstratione quia et ex effectibus), ya que estos últimos dejan a nuestro intelecto en la duda en relación con las propiedades que se manifiestan en ellos, o bien lo inducen a error. Eso ocurre, por ejemplo, con la Trinidad y con el carácter contingente del actuar de la esencia divina. De hecho, una de las propiedades de la esencia divina es que se comunica a las tres personas divinas; sin embargo, los efectos del actuar de la esencia divina que se manifiestan en las criaturas no muestran tal comunicabilidad, ya que Dios no actúa sobre ellas en cuanto trino, sino que en cuanto uno. Por ende, una demostración a partir de los efectos conduciría al error respecto a la Trinidad, ya que se supone que a un sujeto no le corresponde más que una sola naturaleza, y entonces la razón natural podría más bien negar la Trinidad antes que afirmarla. Algo similar ocurre con el carácter contingente de las acciones de la esencia divina y de las sustancias separadas en general, ya que muchos filósofos han afirmado su eternidad y el carácter necesario de sus acciones, en lugar de proponer un actuar contingente y que se despliegue en el tiempo ${ }^{30}$.

Duns Scoto plantea luego una objeción a este argumento, que en cierta medida se encontraba ya en el tercer argumento de los filósofos. De acuerdo con ella, toda propiedad necesaria de las sustancias separadas que el hombre es capaz de conocer en esta vida por fe o por la revelación común -es decir, que se encuentra en la Sagrada Escritura-, también puede ser conocida de manera natural. Lo anterior se desprende

\footnotetext{
${ }^{28}$ Cf. Duns Scoto, Ordinatio prólogo, n. 40, I 22-23; Aristóteles, Metaph. I c. 2, 982a 8-10, AL XXV 3.2 14: "Existimamus sapientem omnia maxime scire ut contingit, non singularem scientiam eorum habentem"; ibíd., 982a 21-23, AL XXV 3.2 15: "Omnia scire universalem scientiam maxime habenti inesse necesse est; hic enim novit omnia aliqualiter subiecta".

${ }^{29}$ Cf. Duns Scoto, Ordinatio prólogo, n. 41, I 23.

${ }^{30}$ Cf. Duns Scoto, Ordinatio prólogo, n. 41, I 23-25. Scoto enumera otras determinaciones que los filósofos consideran propias de las sustancias separadas, como por ejemplo que el número de las sustancias separadas está relacionado al número de los movimientos del cielo, o bien que son por naturaleza bienaventuradas o incapaces de pecar, todo lo cual nuestro Doctor estima absurdo.
} 
del hecho de que todo aquello cuyos términos pueden ser conocidos de modo natural, puede ser conocido él mismo en particular del mismo modo. Y así, puesto que el hombre conoce de manera natural los términos de las propiedades necesarias que se dan a conocer mediante la Revelación, podría de igual modo conocer dichas propiedades prescindiendo de esta última ${ }^{31}$.

Esto se demuestra lógicamente, ya que la relación entre los términos y las propiedades necesarias puede ser inmediata o mediata. En el primer caso, dichas propiedades se conocen una vez que se han aprehendido los términos. En el segundo caso, se pueden llegar a concluir dichas propiedades -que constituyen un término medio entre los extremos ya conocidos- conjugándolas con ellos. Si de esa conjunción resulta una premisa inmediata, se puede dar por conocida la propiedad; si la premisa es mediata, se vuelve a conjugar con los extremos, hasta que se alcance una premisa inmediata. Por ende, es posible conocer las propiedades mediatas naturalmente a partir de términos inmediatos. Asimismo, si se da una discusión entre uno que tiene fe y otro que no cree, no se discute sobre nombres, sino que sobre los conceptos aludidos por ellos; por lo tanto, lo que uno afirma por fe el otro lo comprende por la razón natural ${ }^{32}$.

En su respuesta, nuestro Doctor examina en qué sentido es posible conocer algo de manera deductiva, para que queden de manifiesto los límites del conocimiento natural. Scoto parte asumiendo que hay algunas verdades inmediatas de las sustancias separadas, de entre las cuales escoge una cualquiera, que llama $a$. En ella se incluyen muchas verdades mediatas, como las que afirman de modo particular aspectos comunes del predicado a aspectos comunes del sujeto. Dichas verdades mediatas se pueden llamar $b, c$, etc. La evidencia de su verdad depende del conocimiento de algo inmediato, de tal modo que dicha verdad no puede ser conocida sino a partir de eso inmediato. Por lo tanto, si un intelecto fuera capaz de entender y conjugar los términos mediatos ( $b, c$, etc.), pero no de entender los términos de $a$ ni, por ende, $a$ mismo, el conocimiento que tendría de $b$ poseería un carácter neutro, ya que su verdad no es evidente por $b$ o $c$, ni menos aún por el término inmediato $a$, que no conoce.

Eso ocurriría con el conocimiento humano de las sustancias separadas en esta vida, ya que el hombre posee conceptos que son comunes a las sustancias materiales e inmateriales, que se pueden conjugar entre sí para formar proposiciones complejas sobre dichas sustancias. Sin embargo, en la medida en que la evidencia de la verdad de esas proposiciones depende a su vez del conocimiento de las verdades inmediatas de las sustancias -concebidas a partir de su razón propia y especial-, resulta que el hombre no es capaz de conocer dicha verdad, ya que no concibe las sustancias según su razón propia y particular ${ }^{33}$.

\footnotetext{
${ }^{31}$ Cf. Duns Scoto, Ordinatio prólogo, n. 42, I 25.

${ }^{32}$ Cf. Duns Scoto, Ordinatio prólogo, n. 43-44, I 25-26.

${ }^{33}$ Cf. Duns Scoto, Ordinatio prólogo, n. 45, I 26-27.
} 
Así, por ejemplo, si no se pudiera concebir el triángulo a partir de su razón propia, de la que se concluye que es la primera figura, se podría sin embargo abstraer la noción general de 'figura' del cuadrado y la de 'primera' de los números, y así se podría proponer que 'hay alguna figura que es la primera'. Dicha proposición, sin embargo, a pesar de que los términos que la componen son comprensibles, poseería un carácter neutro para quien no conoce el triángulo, ya que es mediata y se incluye en la proposición inmediata 'el triángulo es la primera figura'. Por ende, si no se puede conocer la proposición inmediata, a través de la cual queda en evidencia la verdad de las demás proposiciones mediatas, es imposible afirmar la verdad de estas últimas, sino solamente como una verdad probable ${ }^{34}$.

Scoto niega, entonces, que a partir del conocimiento de los términos en los que están contenidas las verdades necesarias de las sustancias separadas se pueda conocer a ciencia cierta lo que es propio de ellas, ya que, dado que esas verdades necesarias son mediatas, no poseen en sí mismas el fundamento de su verdad. Pero su respuesta se hace más interesante cuando distingue entre los términos medios que están ordenados de manera esencial a los extremos y aquellos que son particulares. En el primer caso -en que el término medio puede ser parte de uno de los extremos, o bien una determinación anterior de otra posterior-, dado que a través del término medio se puede concluir de manera universal que un extremo está contenido en el otro o bien que se excluyen mutuamente, el Doctor Sutil admite que quien conoce los extremos puede entender también el término medio. En cambio, si el término medio es particular, no corresponde que quien concibe los extremos generales sea capaz de entender el término medio particular que está ordenado a los extremos, dado que se encuentra contenido solo en uno de ellos y no está ordenado de manera esencial a ambos.

Ese sería el caso del intelecto humano en vistas del conocimiento de las sustancias separadas, ya que la quiditas, de acuerdo con su razón propia y particular -ya que posee una determinación inmediata inherente solo a ella-, constituye un término medio inferior respecto al concepto común del cual se predica aquella determinación concebida en sentido general, y por ende no permite que se deduzca dicha determinación en general, sino solo en particular. El ejemplo del triángulo sirve para ilustrar esta conclusión, ya que no necesariamente alguien que conciba la noción de figura y la de primacía en general será capaz de concebir el triángulo en particular, ya que este último es un término medio contenido en la noción de figura que permite solamente concluir la primacía de una figura en particular, a saber, de sí mismo ${ }^{35}$.

Luego, a partir de las objeciones a los argumentos de los filósofos, y en particular de acuerdo con lo que afirma en el último argumento, es posible advertir que para Scoto -al menos respecto al modo en que el intelecto humano es capaz de conocer la

\footnotetext{
${ }^{34}$ Cf. Duns Scoto, Ordinatio prólogo, n. 46, I 27-28.

${ }^{35}$ Cf. Duns Scoto, Ordinatio prólogo, n. 47, I 28-29.
} 
realidad-no habría una exclusión mutua entre conocimiento natural y sobrenatural, a pesar de la diferencia que se da entre ellos. En este sentido, dicha diferencia radicaría más bien en el hecho de que, de acuerdo con las condiciones en que el hombre conoce en esta vida, su intelecto no puede alcanzar el conocimiento ni de Dios en cuanto tal, ni de las sustancias separadas en sí, ni de los términos particulares a partir de los cuales se podría concluir aquello propio de ambos, que en último término movería al hombre a encaminarse para ser digno de contemplar a Dios eternamente. Las condiciones en que el hombre conoce en esta vida son, en efecto, naturales. Por ende, para determinar dónde radica la diferencia entre natural y sobrenatural, a fin de que quede claro en qué consiste el conocimiento sobrenatural, nuestro Doctor estima necesario examinar la noción de 'natural'.

\title{
3. La distinción escotista entre 'natural' y 'naturaleza' y el sentido en que se debe entender la necesidad de una doctrina revelada
}

Para determinar en qué consiste el conocimiento sobrenatural, Duns Scoto examina la noción de 'natural'. Su examen propone la distinción de dos sentidos a partir de los cuales es posible concebir dicha noción y en qué sentido se opone a la de sobrenatural. Dice nuestro Doctor:

\begin{abstract}
Ahora bien, debemos comparar una potencia receptiva ya sea con el acto que recibe, o bien con el agente del cual recibe dicho acto. En el primer modo, se trata de una potencia natural, violenta o neutra. Se llama natural, si se inclina naturalmente [a ese acto]; violenta, si va contra la inclinación natural de quien recibe el acto; y neutra, si no se inclina naturalmente a la forma que recibe ni a la opuesta. Sin embargo, en esta comparación no se da nada sobrenatural. Pero si comparamos a quien recibe con el agente a partir del cual recibe la forma, entonces tenemos un carácter natural cuando el que recibe se compara con un agente que por su naturaleza está determinado de tal modo, que puede imprimir naturalmente su forma en aquel paciente, y un carácter sobrenatural, en cambio, cuanto se compara con un agente que no puede imprimir naturalmente su forma en aquel paciente ${ }^{36}$.
\end{abstract}

Lo primero que llama la atención de este párrafo -que prepara la respuesta a la cuestión principal sobre la necesidad de una doctrina que supera el conocimiento

\footnotetext{
${ }^{36}$ Cf. Duns Scoto. Ordinatio prólogo, n. 57, I 35: "Potentia enim receptiva comparatur ad actum quem recipit, vel ad agentem a quo recipit. Primo modo ipsa est potentia naturalis, vel violenta, vel neutra. Naturalis dicitur si naturaliter inclinatur, violenta si sit contra naturalem inclinationem passi, neutra si neque inclinetur naturaliter ad illam formam quam recipit neque ad oppositam. In hac autem comparatione nulla est supernaturalitas. Sed comparando receptivum ad agens a quo recipit formam, tunc est naturalitas quando receptivum comparatur ad tale agens quod natum est naturaliter imprimere talem formam in tali passo, supernaturalitas autem quando comparatur ad agens quod non est naturaliter impressivum illius formae in illud passum".
} 
natural- es que el punto de partida sea la doctrina que se intenta superar, a saber, la de Aristóteles $^{37}$. En este sentido, no se puede pensar que se trate de un mero reconocimiento de la autoridad del Filósofo. Su doctrina, de hecho, constituye la base especulativa de la de nuestro Doctor. Eso no significa, sin embargo, que la acepte sin más e intente encontrar una armonía entre ella y la doctrina cristiana, sino que queda en claro que solo se sirve de ella como punto de partida, para afirmar algo que no se concluye de ella, a saber, que aparte del conocimiento natural es posible alcanzar otro más alto, de origen sobrenatural. Como se verá luego, Scoto parece tener conciencia de este giro, y también de sus límites cuando se trata de convencer de la verdad de la doctrina sobrenatural a aquellos que, si bien la pueden comprender, no creen en ella.

\subsection{Los sentidos de lo natural, a partir de sus nociones opuestas}

El Doctor Sutil distingue dos sentidos de 'natural', de acuerdo con el carácter del acto que recibe una potencia receptiva, o del agente que produce dicho acto. Cabe destacar que aquello común que permite la distinción de los sentidos de 'natural' es la noción de potencia receptiva, en vistas del acto o del agente capaz de consumarla. Así, en el primer caso, que trata de la relación entre la potencia receptiva y el acto que la perfecciona, Scoto opone lo violento y lo neutro a lo natural. En este sentido, la relación entre la potencia activa y pasiva tendrá un carácter natural, si esta última se inclina según su propia naturaleza hacia el acto que la perfecciona, ya que entre ambos se complementan. Dicho carácter será violento, si el acto que recibe la potencia pasiva es contrario a su naturaleza, en la medida que la presencia de dicho acto en ella le impide que acoja el acto que sí le permitiría alcanzar su determinación propia.

\footnotetext{
${ }^{37}$ En efecto, Aristóteles distingue entre natural, violento y neutro en varios de sus escritos (el lugar clásico es Phys. IV c. 8, 215a 1-6, AL VII ${ }^{1}$ 159-160), y la distinción entre intelecto agente y paciente -entendida según la interpretación de Averroes- era el sentido corriente en que se concebía la acción del intelecto en el siglo XIII: cf. Aristóteles, De anima III c. 5, 430a 10-25. Translatio nova Guillelmi de Moerbeka, en: S. Tomás de Aquino, Sententia libri De anima, $\mathrm{XLV}^{1}$ 218; Averroes, Commentarium magnum super libros De anima III c. 18-20. Ed. F. S. Crawford. Corpus Commentariorum Averrois in Aristotelem, Versiones Latinae, vol. VI ${ }^{1}$, The Medieval Academy of America, Cambridge, MA 1953, pp. 437-454. Para una discusión más detallada sobre estos asuntos, véase Belo, C. "The Concept of 'Nature' in Aristotle, Avicenna and Averroes", en Kriterion (Belo Horizonte) 131 (2015), pp. 45-56; Bowman, L. J. "The Development of the Doctrine of the Agent Intellect in the Franciscan School of the Thirteenth Century", en The Modern Schoolman 50 (1973), pp. 251-279; Dales, R. C. The Problem of the Rational Soul in the Thirteenth Century, Brill, Leiden - New York - Köln 1995; Guzmán Manzano, I. "Naturaleza cognoscitiva de la intelección, según Escoto", en Antonianum 49 (1974), pp. 72-96; Puig Montada, J. “Averroes y el entendimiento", en Revista Española de Filosofía Medieval 9 (2002), pp. 49-62; Weber, E.-H. La persone humaine au XIII siècle. Vrin, Paris 1991, pp. 287-369; Zagal, H. "On Intellectus Agens and Aristotelian Separate Substances: Aquinas' Waterloo", en Kriterion (Belo Horizonte) 111 (2005), pp. 117-137.
} 
Finalmente, el carácter de esa relación será neutro, si la potencia receptiva no tiende por sí misma hacia la forma que recibe del acto que acoge, pero dicha forma tampoco impide que la potencia pasiva alcance su propia determinación ${ }^{38}$.

De lo anterior se desprende que, no obstante las tres nociones se excluyan entre sí, la potencia pasiva siempre recibe una forma de parte del agente, y ello le permite alcanzar una consumación, a pesar de que solo cuando la potencia activa corresponde con la determinación esencial de la potencia pasiva - es decir, cuando la acción es natural- esta última se consuma en propiedad. En vista de ello, nuestro Doctor sostiene que:

Comparando el intelecto posible con la noticia actual en sí, no hay un conocimiento sobrenatural, porque el intelecto posible se perfecciona naturalmente por cualquier conocimiento, y está inclinado naturalmente a cualquier conocimiento ${ }^{39}$.

Esta afirmación no solo se refiere al conocimiento natural, sino que también en cierta medida al sobrenatural que se puede alcanzar en esta vida. En efecto, si bien Scoto continúa diciendo que se puede hablar de un conocimiento sobrenatural -el cual "se genera a partir de un agente que no está determinado por su naturaleza (quod non est natum) a mover al intelecto posible a un conocimiento tal de manera natural" ${ }^{40}$ - solo a partir de la relación entre la potencia pasiva y el agente del cual proviene el conocimiento, admite la posibilidad de tomar conocimiento de las nociones simples de manera natural en el sentido en que lo sostiene Aristóteles, esto es, mediante la acción de los únicos agentes determinados por su naturaleza a mover al intelecto pasivo, el intelecto agente y las imágenes (phantasmata $)^{41}$.

Nuestro Doctor admite dicha posibilidad porque distingue dos sentidos en que se da a conocer un objeto, complejo e incomplejo. Así, solo de este último modo el hombre es capaz de conocer de manera natural los elementos a partir de los cuales se

\footnotetext{
${ }^{38}$ Scoto, en una revisión de esta cuestión, añadió dos objeciones para aclarar la diferencia entre las distintas nociones en examen. La primera sostiene que la distinción entre 'natural' y 'violento' también debe ser considerada según la relación entre el agente y la potencia pasiva, y no solo entre esta última y el acto que la perfecciona. La segunda, que la comparación entre 'natural' y 'sobrenatural' se debe tomar igualmente a partir del acto que perfecciona a la potencia pasiva. El Doctor Sutil, junto con responder a esas objeciones, se remite para la exposición de sus argumentos a una de las cuestiones sobre la resurrección, cf. Duns Scoto, Ordinatio IV, d. 43 n. 238-242, XIV 73-74; ibíd. prólogo, n. 5859, I 35-37.

${ }^{39}$ Duns Scoto, Ordinatio prólogo, n. 60, I 37: “Comparando intellectum possibilem ad notitiam actualem in se nulla est sibi cognitio supernaturalis, quia intellectus possibilis quacumque cognitione naturaliter perficitur et ad quamcumque cognitionem naturaliter inclinatur".

${ }^{40}$ Ibíd.: "Sed secundo modo loquendo [scilicet, comparando intellectum possibilem ad agentem a quo recipit notitiam], sic est supernaturalis [cognitio] quae generatur ab aliquo agente quod non est natum movere intellectum possibilem ad talem cognitionem naturaliter".

${ }^{41}$ Cf. Duns Scoto, Ordinatio prólogo, n. 60-61, I 37-38; Aristóteles, De an. III c. 4, 429a 13-18, XLV ${ }^{1}$ 201; c. 5, 430a 14-17, XLV 218; c. 7, 431a 14-17, XLV1 229; c. 8, 432a 8-10, XLV 235.
} 
compone el conocimiento del objeto sobrenatural, ya que son comunes a los objetos naturales. Este es un punto crucial para entender el giro en relación con la posición de los filósofos, ya que aquí concuerda en parte con la objeción al tercer argumento teológico -que el intelecto humano comprende los términos de la doctrina revelada de manera natural-, y la vez se remite a un presupuesto ontológico y gnoseológico fundamental de dicha afirmación, que sostiene que hay un concepto común a Dios y a las criaturas -el concepto de ser-, que posee un carácter unívoco ${ }^{42}$. Scoto sostiene que este tipo de conocimiento, según el cual es posible concebir el objeto sobrenatural a partir de lo que posee en común con las criaturas, es aquel que según la ley general posee el hombre en esta vida, es decir, el conocimiento que puede alcanzar en esta vida el intelecto humano a partir de los primeros principios del conocimiento.

El alcance -es decir, los límites- de ese tipo de conocimiento queda de manifiesto en vista de las verdades complejas del objeto sobrenatural. Scoto sostiene que, con la sola acción del intelecto agente y las imágenes, muchas de esas verdades complejas -necesarias para la salvación del ser humano- serán ignoradas, o bien tendrán un carácter neutro. Así, para tomar conocimiento de dichas verdades, es necesario que se le pongan de manifiesto al hombre de manera sobrenatural, ya que mediante la sola acción del intelecto agente y de las imágenes el hombre no es capaz de alcanzarlas ni de enseñarlas a otro, debido precisamente al carácter neutro de ese conocimiento. Es por ello que la Revelación, que pone de manifiesto en primer lugar lo que es proprio del objeto sobrenatural, se considera una doctrina sobrenatural, porque proviene de un agente que no mueve de manera natural el intelecto humano en esta vida ${ }^{43}$.

Asimismo, es posible afirmar que una acción o noticia posee un carácter sobrenatural en la medida en que proviene de un agente que suple la operación del objeto sobrenatural. En este sentido, el único objeto determinado por su naturaleza (quod natum est) a dar a conocer lo que es propio de la esencia divina es ella misma, conocida según su propia razón. De hecho, el objeto sobrenatural consiste precisamente en la esencia divina, en cuanto que se da a conocer como tal. Sin embargo, el hombre no es capaz de conocer dicha esencia en cuanto tal en esta vida por medios naturales, ya que ella se da a conocer de manera natural solo a sí misma, en la medida en que consiste en un objeto voluntario, y por ende no se da a conocer perfectamente a las criaturas de manera natural, ni por sí misma ni mediante otra sustancia ${ }^{44}$.

\footnotetext{
${ }^{42}$ Cf. Duns Scoto, Ordinatio I, d. 3 n. 24-62, III 15-44; Guerrero Troncoso, "Los presupuestos metafísicos de la univocidad en Duns Scoto", en Revista Chilena de Estudios Medievales 7 (2015), pp. 11-32.

${ }^{43}$ Cf. Duns Scoto, Ordinatio prólogo, n. 62, I 38.

${ }^{44}$ Cf. Duns Scoto, Ordinatio I, d. 3 n. 57, III 39: "Deus ut haec essentia in se, non cognoscitur naturaliter a nobis, quia sub ratione talis cognoscibilis est obiectum voluntarium, non naturale, nisi respectu sui intellectus tantum. Et ideo a nullo intellecto creato potest sub ratione huius essentiae ut haec est naturaliter cognosci, nec aliqua substantia naturaliter cognoscibilis a nobis sufficienter ostendit hanc essentiam ut haec, nec per similitudinem univocationis nec imitationis".
} 
Ahora bien, si aquello que es propio de la esencia divina se da a conocer por medio de un agente distinto de ella, este agente suple la operación propia de dicha esencia, y ahí radica su carácter sobrenatural. En el caso de que ese agente fuera capaz de poner de manifiesto de modo perfecto todo lo que es propio de la esencia divina, supliría su operación perfectamente. Asimismo, no obstante lo imperfecta que sea la manifestación del objeto sobrenatural que el agente sea capaz de causar, de cualquier manera se encontraría contenida virtualmente en esa perfecta, cuya causa es el objeto sobrenatural en cuanto tal. En este sentido, quien revela que Dios es Trino, por ejemplo, pone de manifiesto una verdad que es propia de la esencia divina, aunque sea de manera oscura. La oscuridad de dicha manifestación se debe al hecho de que la esencia divina no se da a conocer en cuanto tal, ya que si lo hiciera, el conocimiento de la Trinidad y de sus demás propiedades sería claro y perfecto. Por otra parte, a pesar de lo oscura e imperfecta que sea la manifestación que causa el agente que suple la operación del objeto sobrenatural, siempre pone en evidencia algo propio de este último, sobre todo porque la esencia divina se manifiesta a través de aquellos agentes que suplen su operación, ya que no hay ningún objeto, de todos los que son capaces de mover el intelecto humano naturalmente, que contenga en sí de manera virtual una manifestación de las verdades de la esencia divina, ni clara ni oscura ${ }^{45}$.

Por último, Scoto separa los dos modos en que se concibe el carácter sobrenatural del conocimiento revelado para que quede clara su diferencia. En este sentido, si un agente sobrenatural infundiera en alguien el conocimiento de un objeto natural como si aprendiera geometría sin necesidad de estudiarla, por ejemplo-, dicho conocimiento sería sobrenatural solo en el primer sentido y no en el segundo, esto es, solo en la medida en que proviene de un agente que no está determinado por su naturaleza a causar dicho conocimiento, y no porque se ponga de manifiesto algo proprio de la esencia divina por un agente que suple su operación. El primer sentido no implica el segundo, pero este último sí implica el primero. Resulta entonces que, si hay un conocimiento que el intelecto puede alcanzar de modo natural, no es necesario que lo adquiera por medio de un agente sobrenatural; en cambio, si hay un conocimiento que proviene de un agente que suple la operación del objeto sobrenatural, es menester que posea un carácter sobrenatural, ya que no se puede alcanzar naturalmente ${ }^{46}$.

Una vez concluida su respuesta, y antes de contestar a los argumentos de los filósofos en particular, el maestro franciscano presenta algunas sentencias de san Agustín para confirmar su solución y responder a una objeción, con lo cual queda en claro cómo se debe entender el carácter necesario del conocimiento sobrenatural ${ }^{47}$. Sin embargo, en la tercera de ellas, que sostiene -siguiendo a san Agustín- que "de todo aquello que para nuestros sentidos es remoto, ya que no lo podemos conocer

\footnotetext{
${ }^{45}$ Cf. Duns Scoto, Ordinatio prólogo, n. 63-64, I 38-40.

${ }^{46}$ Cf. Duns Scoto, Ordinatio prólogo, n. 65, I 40.

${ }^{47}$ Cf. Duns Scoto, Ordinatio prólogo, n. 66-71, I 41-44.
} 
por nuestro testimonio, necesitamos del testimonio de otros" ${ }^{\prime 4}$, Scoto señala que es precisamente el carácter neutro de las proposiciones complejas que se pueden formular de la esencia divina lo que nos hace dudar de nuestro testimonio, y por ello se requiere de un testimonio sobrenatural, que provenga de alguien que sea más grande que toda la especie humana. Por otra parte, resulta que no se sabe a ciencia cierta cómo tuvo lugar esa primera Revelación, si mediante un discurso interno o externo, o a través de signos. Ante la duda, basta con el hecho de que haya sido posible que esa doctrina se revelara de manera sobrenatural. Sin embargo, señala el maestro franciscano, en ningún caso ella pudo haber sido expuesta en primer lugar por un hombre sin ningún error ${ }^{49}$. Se hará una elucidación del alcance de esta afirmación -que al parecer pone en cuestión la validez de la Revelación-en la próxima sección. Antes de pasar a ella, se concluirá la exposición de los sentidos de 'naturaleza' y 'natural' con una de las afirmaciones más elocuentes de Scoto sobre el modo en que el intelecto humano es capaz de alcanzar su consumación en esta vida mediante una doctrina sobrenatural.

\subsection{Los sentidos de naturaleza y la relación del ámbito de las criaturas con Dios}

Dicha afirmación se encuentra en la respuesta a la confirmación del primer argumento de los filósofos, la cual sostiene que a toda potencia pasiva natural le debe corresponder una potencia activa natural que permita que su capacidad se consume, ya que si en la naturaleza no hubiera nada en virtud de lo cual pudiera alcanzar su consumación, su presencia sería en vano ${ }^{50}$. Scoto prepara su respuesta señalando que en Aristóteles se pueden advertir dos sentidos de naturaleza. Según el primero, naturaleza es el principio intrínseco del movimiento y del reposo, mientras que el segundo sentido la considera como un principio activo natural, opuesto a la técnica y a la acción intencional del intelecto, sin que su carácter intrínseco o extrínseco posea mayor relevancia ${ }^{51}$.

Nuestro Doctor considera que en ningún caso se puede conceder que, si no existe un principio natural activo, la potencia natural pasiva sería en vano. En el primer caso, porque hay muchas potencias pasivas a las que no les corresponde un principio activo intrínseco, en la medida en que el principio activo que las pone a su vez en acto es extrínseco. En el segundo caso, para algunas potencias pasivas dicha afirmación es incluso falsa. Eso es lo que ocurre cuando una naturaleza -es decir, un ser natural-, debido a su carácter excelente, se dispone de manera natural a recibir

\footnotetext{
${ }^{48}$ Cf. s. Agustín de Hipona, De civitate Dei XI c. 3. Ed. B. Dombart - A. Kalb. Corpus Christianorum Series Latina, vol. XLVIII, Brepols, Turnholt 1955, p. 323.

${ }^{49}$ Cf. Duns Scoto, Ordinatio prólogo, n. 68-69, I 42-43.

${ }^{50}$ Cf. Duns Scoto, Ordinatio prólogo, n. 7, I 5-6; supra, sección 2.1.

${ }^{51}$ Cf. Aristóteles, Phys. II c. 1, 192b 20-23, AL VIII ${ }^{4} 4$; ibíd., c. 5, 196b 17-22, AL VII' ${ }^{1}$ 68; Duns Scoto, Ordinatio prólogo, n. 73, I 44-45.
} 
una perfección de tal magnitud, que no puede ser causada en virtud de un agente natural ${ }^{52}$.

Asimismo, contra la prueba de la afirmación de los filósofos -si faltara una potencia activa natural, la potencia pasiva sería en vano en la naturaleza, ya que no podría alcanzar su consumación-, Scoto sostiene que el hecho de que una potencia pasiva carezca de una respectiva potencia activa que le permita de modo principal -es decir, por sí mismo- alcanzar su consumación, no implica necesariamente que se encuentre en vano en la naturaleza, en la medida en que dicho agente puede operar de tal manera que mueva a la potencia pasiva para que se disponga a recibir la acción de un agente mayor que él -como puede serlo un agente primero o sobrenatural-que esté presente en la naturaleza -entendida como la totalidad ordenada de todo lo que es-, el cual le permitirá alcanzar su consumación de manera completa ${ }^{53}$.

Es aquí donde se encuentra otro punto crucial de la respuesta del Doctor Sutil, que a su vez la deja expuesta a una objeción por parte de los filósofos. En efecto, es posible concluir a partir de sus afirmaciones que hay algunos seres cuya perfección es tal, que la naturaleza en cuanto totalidad no es capaz por sí sola de permitirles alcanzar su propia consumación. Dado que esos seres forman parte de dicha totalidad, se podría afirmar que la naturaleza en su conjunto carecería de algo que es necesario para que tenga lugar su propia perfección, y por ende sería incompleta en sí misma. Con ello, entonces, se rebajaría la perfección de la naturaleza, ya que ella poseería un carácter incompleto y carente, que no le permitiría alcanzar por sí sola su propia consumación. El Doctor Sutil advierte este problema, y lo responde del siguiente modo:

Y si se plantea una objeción, diciendo que esto, el hecho de que no pueda alcanzar su perfección propia a partir de [las condiciones] naturales envilece a la naturaleza, dado que la naturaleza es menos carente en aquello que es más noble -de acuerdo con De caelo et mundo II- respondo así: si nuestra felicidad consistiera en la especulación suprema que podemos alcanzar ahora naturalmente, el Filósofo no diría que la naturaleza carece de lo que le es necesario ${ }^{54}$. Pues bien, concedo que dicha especulación puede alcanzarse ahora de manera natural y, más aun, sostengo que otra más alta aún se puede recibir naturalmente. Por lo tanto, la naturaleza se dignifica con esto más que si se afirma que la especulación más alta es aquella natural;

\footnotetext{
${ }^{52}$ Cf. Duns Scoto, Ordinatio prólogo, n. 73, I 45.

${ }^{53}$ Cf. Duns Scoto, Ordinatio prólogo, n. 74, I 45.

${ }^{54}$ Cf. Aristóteles, De an. III c. 9, 432b 21-22, XLV1 238b: "Si igitur natura non facit frustra nihil, neque deficit in necessariis"; De caelo II c. 8, 290a 30-35. Translatio Michaelis Scoti, en Averroes, Commentum magnum super libro De caelo et mundo Aristotelis, ed. F. J. Carmody - R. Arnzen, Peeters, Leuven 2003, vol. II, p. 370: "Et dicamus etiam quod extra rationem est ut natura ponat stellas motas et non dedit eis instrumentum motus: natura autem nihil ponit otiose sine causa. Et impossibile est ut natura esset ingeniata in animalibus, et dimisisset haec corpora habentia utiles dispositiones, et abstulisset eis ea per quae possent moveri per se, et removit eas a rebus habentibus instrumentum motus".
} 
y no hay de qué asombrarse si la capacidad pasiva de una naturaleza cualquiera se extiende a una perfección mayor que aquella a la que lo hace su causalidad activa ${ }^{55}$.

Aquí ya es posible apreciar que en la oposición entre potencia pasiva y potencia activa radica el fundamento de la reflexión de Scoto sobre la naturaleza y lo natural. En efecto, como se vio al comienzo de esta sección, dicha oposición constituye el punto de partida de la determinación del sentido en que lo sobrenatural se contrapone a lo natural. Ahora, permite distinguir los términos en que se concibe el modo de ser de los seres naturales, y cómo el ámbito de dichos seres puede ser complementado -o más bien completado- en la medida en que se encuentra con el ser supremo. En este sentido, la noción de potencia pasiva se halla implícita en la determinación de 'naturaleza' como modo de ser, ya que en las dos instancias que señala Scoto -en cuanto principio intrínseco del movimiento y del reposo, y en oposición a los otros principios activos- se remiten a la definición aristotélica de potencia como principio del movimiento o de la transformación en otro o en cuanto otro ${ }^{56}$.

Así, en el primer caso, la naturaleza consiste en una potencia intrínseca -tanto activa como pasiva - en virtud de la cual un ser natural tiende a su consumación en la medida en que lleva a cabo y recibe diversas acciones mediante las cuales despliega su determinación propia. A través de dicho actuar, la potencia determina la relación de ese ser con su entorno, que es entendido como el conjunto de condiciones que permiten o impiden que un ser natural alcance su consumación, pero no como aquello que lo determina en tanto tal o cual ser, o bien que lo mueve en primer lugar a desplegar su propia naturaleza. De acuerdo con el segundo sentido, en cambio, la naturaleza se concibe en contraposición a las otras dos potencias activas, que poseen en común el hecho de poseer algún grado de contingencia, a diferencia de la acción de la naturaleza, que es necesaria, en el sentido de que, si se dan las condiciones para que algo ocurra de manera natural, eso ocurre ${ }^{57}$.

Este segundo sentido, que opone la naturaleza en cuanto principio activo al arte y a la acción intencional, prepara la respuesta definitiva de nuestro Doctor, y permite

\footnotetext{
${ }^{55}$ Cf. Duns Scoto, Ordinatio prólogo, n. 75, I 45-46: "Et si obicitur quod istud vilificat naturam quod ipsa non possit consequi perfectionem suam ex naturalibus, cum natura minus deficiat in nobilioribus, ex II De caelo et mundo, respondeo: si felicitas nostra consisteret in speculatione suprema ad qualem possumus nunc naturaliter attingere, non diceret Philosophus naturam deficere in necessariis. Nunc autem illam concedo posse haberi naturaliter, et ultra, dico aliam eminentiorem posse recipi naturaliter. Igitur in hoc magis dignificatur natura, quam si suprema sibi possibilis poneretur illa naturalis; nec est mirum quod ad maiorem perfectionem sit capacitas passiva in aliqua natura quam eius causalitas activa se extendat".

${ }^{56}$ Cf. Aristóteles, Metaph. V c. 12, 1019a 15-16, AL XXV ${ }^{3.2}$ 108: "Potestas dicitur haec quidem principium motus aut mutationis aut in altero aut in quantum alterum".

${ }^{57}$ Cf. Duns Scoto, Ordinatio prólogo, n. 6, I 3: "Activo naturali et passivo simul approximatis et non impeditis sequitur actio necessario", con referencia a Aristóteles, Metaph. IX c. 10, 1048a 6-8 (véase la nota 12).
} 
advertir la distancia que éste toma de una posición puramente filosófica. El hecho de que una potencia natural pasiva pueda ser consumada por la naturaleza, por el arte o por una acción intencional, demuestra que la potencia pasiva es más amplia que su contraparte activa. En efecto, una lenteja es capaz de convertirse en planta, de terminar en un collar artesanal, o en una sopa, dependiendo del agente del cual recibe la acción, y en los tres casos se consuma algo de lo que es capaz, aún cuando eso no sea lo más propio de su esencia. Esto pone de manifiesto, entonces, que nuestra experiencia cotidiana nos muestra constantemente que las potencias pasivas se consuman por un agente que no es aquel que le corresponde de acuerdo con su naturaleza propia.

En lo que respecta al conocimiento sobrenatural, sin embargo, Scoto va más allá de este ejemplo, y usa la doctrina de Aristóteles como fundamento de su propia posición como teólogo. En primer lugar, nuestro Doctor afirma -siguiendo al Filósofoque cuanto más perfecto es un ser natural, con mayor razón debe contar con todo lo necesario para alcanzar su propia consumación de manera natural, ya sea porque aquello que lo constituye en cuanto tal es suficiente para su perfección, o bien porque posee alguna propiedad en virtud de la cual es capaz de llevar a cabo acciones que aseguran que alcanzará su consumación ${ }^{58}$. En lo que respecta a la felicidad humana, sin embargo, Scoto parece interpretar la afirmación de que la naturaleza no carece de aquello que le es necesario en el sentido de que el Filósofo concedería que, si la naturaleza humana solo pudiera aspirar a conocer aquello que se manifiesta por la acción del intelecto agente y las imágenes, no podría contemplar las sustancias separadas en cuanto tales y, por lo tanto, tampoco sería capaz de alcanzar completamente su felicidad, porque no contaría con aquello que se requiere para dicha contemplación ${ }^{59}$.

\footnotetext{
${ }^{58}$ Compárese con lo que sostiene Enrique de Gante (Summa a. 1 q. 4 ad 2, XXI 109): "Natura non dicitur deficere in necessariis quando dat illa per quae omnia necessaria possunt acquiri, licet ipsa immediate non confert [...]. Distinguendum tamen quod quaedam sunt necessaria ad esse, quaedam ad bene esse. In necessariis primo modo numquam natura deficit alicui speciei, quin omnia sibi necessaria immediate confert ei. In necessariis autem secundo modo similiter non deficit ei, quia illi quae illa sibi acquirere non potest dat immediate ea per quae illa sibi acquirere potest. Unde natura dicitur illa dare, quia licet non dat illa immediate, dat tamen illa per quae acquirere potest ea".

${ }^{59}$ Es difícil entender este pasaje de Scoto, porque parece contradecir lo que sostiene Aristóteles, que la naturaleza no carece de aquello que necesita para su consumación. Los traductores italianos dan a entender que se puede asimilar el hecho de que las estrellas dependan de la naturaleza para su movimiento (De caelo II c. 8, 290a 30-35, cf. nota 54) a la carencia por parte del hombre de un órgano que le permita alcanzar una felicidad mayor de la que es capaz en esta vida (cf. la nota ad loc. de la traducción italiana, Prologo dell'Ordinatio, a cura del Seminario Teologico "Immacolata Mediatrice" dei Frati Francescani dell'Immacolata, Frigento: Casa Mariana Editrice 2006, 83). Sin embargo, nuestro Doctor había advertido un tono dubitativo en Aristóteles en relación con la felicidad humana, del cual probablemente se halla un eco en este parágrafo; cf. Duns Scoto, Ordinatio prólogo, n. 14, I 10: "Philosophus sequens naturalem rationem aut ponit felicitatem esse perfectam in cognitione acquisita substantiarum separatarum [...], aut si non determinate asserat illam esse supremam perfectionem nobis possibilem, aliam ratione naturali non concludit, ita quod soli naturali rationi innitendo vel errabit circa
} 
Tales afirmaciones preparan el giro que da nuestro Doctor a la posición de los filósofos en la segunda parte de su respuesta, cuyo eje se encuentra en la noción de 'natural'. En efecto, es de manera natural que el hombre puede alcanzar el conocimiento que sostiene Aristóteles, e incluso un conocimiento mayor del que la naturaleza puede proveer por sí sola. La relación entre el conocimiento sobrenatural y la naturaleza depende de cómo se conciba esta última. Así, por una parte, dicho conocimiento sobrenatural supera la capacidad de la naturaleza, si se la entiende en cuanto principio activo -que aquí sería el intelecto agente y las imágenes-. Asimismo, el conocimiento sobrenatural complementa a la naturaleza concebida en sentido pasivo -en este caso, como intelecto paciente-, y por ello el maestro franciscano dice que, en vez de rebajar a la naturaleza, al afirmar que ella es capaz de acoger en sí una perfección mayor que la que puede llevar a cabo por sí sola, más bien la hace aún más digna.

En este sentido, la naturaleza humana -entendida como potencia pasiva- sería capaz de acoger la manifestación de las sustancias separadas, y más aun, de la esencia divina -el único objeto sobrenatural-, manifestación que le permitiría alcanzar su plena felicidad. Que eso ocurra, sin embargo, no depende de su naturaleza -es decir, de sus capacidades en cuanto potencia activa-, ya que la esencia divina no se da a conocer al intelecto agente y a las imágenes en esta vida, dado que se trata de un objeto voluntario. Así, aunque suene paradojal, el único modo natural en que el hombre podría conocer aquello que es propio de la esencia divina -y que esta última estima conveniente dar a conocer, aunque sea de modo oscuro, "por un espejo y en un enigma" ${ }^{60}$ - sería por medio de una doctrina revelada. Cuál es el alcance que esta afirmación tiene para Scoto, lo veremos en la sección siguiente.

\section{A modo de conclusión. Los límites de una doctrina sobrenatural y del intelec- to humano en esta vida}

Como se señaló al inicio, en este examen se omitieron, por motivos metodológicos, los parágrafos que la Comisión Escotista considera adiciones de Scoto al texto de la Ordinatio, en las que el maestro franciscano corrige, mejora, o incluso comenta su exposición. Tomadas por separado, dos de ellas se pueden considerar como una reflexión de nuestro Doctor sobre los alcances de su posición, y a partir de ellas se plantearán las conclusiones de este trabajo. La primera adición se encuentra al comienzo de la exposición de los argumentos de los filósofos. En ella, en lugar de referirse a esos argumentos en general, el Doctor Sutil se refiere al alcance de la crítica

\footnotetext{
finem in particulari vel dubius remanebit". La edición castellana de J. A. Merino, que consultamos para ayudarnos a elucidar este pasaje, no alude a esta aparente contradicción.

${ }^{60} \mathrm{Cf}$. I Cor. 13, 12: "Videmus nunc per speculum in aenigmate, tunc autem facie ad faciem; nunc cognosco ex parte, tunc autem cognoscam, sicut et cognitus sum".
} 
de los teólogos a la posición de los filósofos, y en general al valor de una doctrina cuya verdad se afirma por la fe, no porque se base sobre una demostración. Dice el maestro franciscano:

Tengamos en cuenta que no se puede poner de manifiesto por la razón natural que algún conocimiento sobrenatural se encuentre presente en el [hombre en cuanto] transeúnte, ni que se lo requiera para alcanzar su perfección; tampoco quien lo posee puede reconocer que está presente en él. Por lo tanto, es imposible hacer uso aquí de la razón natural contra Aristóteles: si se argumenta a partir de algo en lo que se cree, no es razón contra un filósofo, porque [este último] no concede la premisa en la que se cree. Por lo que estas razones presentadas aquí contra él poseen una premisa en la que creemos, o que se prueba por algo en lo que creemos; por ende, no son sino persuasiones teológicas, que van de algo en lo que se cree a otra cosa en la que se cree $^{61}$.

Aunque se podría pensar que con estas palabras nuestro Doctor da por perdida una discusión con los filósofos -ya que podría terminar en un diálogo de sordos-, la observación se vuelve más clara si se la entiende a partir del carácter neutro que posee para Scoto el conocimiento de las propiedades de la esencia divina. En efecto, en la medida en que no hay nada en ellas que lleve al intelecto a reconocer su verdad o falsedad -dado que en esta vida el hombre no conoce perfectamente los términos que las componen, que se encuentran unidos en la esencia divina, y que son los únicos capaces de producir un conocimiento a ciencia cierta del objeto sobrenatural-, lo único que queda para afirmar la verdad de la Revelación es la fe que uno pueda tener en ella. Dicha fe no excluye ni reemplaza la convicción que es consecuencia de la demostración, sino que viene a suplir dicha convicción cuando no hay una demostración posible o concluyente. Sin embargo, si se parte de la base de que los filósofos solo darán por cierto algo que pueda ser demostrado, o cuyos términos sean evidentes para la razón natural, cualquier intento de convencerlos de la verdad de las afirmaciones que se sostienen por la fe no pasará de ser una persuasión teológica, con un carácter meramente probable, jamás concluyente.

La segunda adición permite observar en qué sentido la Revelación se puede entender como una doctrina, y con ello queda más claro el alcance de la primera observación. Ella se encuentra al final de los argumentos teológicos, y discute la posición de Enrique de Gante, no la de los filósofos. Aquí, Scoto opone a la doctrina revelada,

\footnotetext{
${ }^{61}$ Cf. Duns Scoto, Ordinatio prólogo, n. 12, I 9: "Nota, nullum supernaturale potest ratione naturali ostendi inesse viatori, nec necessario requiri ad perfectionem eius; nec etiam habens potest cognoscere illud sibi inesse. Igitur impossibile est hic contra Aristotelem uti ratione naturali: si arguatur ex creditis, non est ratio contra philosophum, quia praemissam creditam non concedet. Unde istae rationes hic factae contra ipsum alteram praemissam habent creditam vel probatam ex credito; ideo non sunt nisi persuasiones theologicae, ex creditis ad creditum".
} 
en cuanto mera enseñanza, el hábito de la teología -es decir, el conocimiento práctico que se tiene de ella-, que sirve para determinar el modo en que se comporta el hombre, ya que lo mueve a actuar de acuerdo con los preceptos de la razón natural. Así, según el maestro franciscano, más importante que conocer la letra de la doctrina revelada es el hecho de conducir la propia vida de acuerdo a cómo está prescrito por dicha doctrina, a pesar de que uno pueda no ser consciente de que el fundamento del propio actuar se encuentra en ella. Al respecto, nuestro Doctor presenta el caso hipotético de un adulto que, a pesar de no haber tenido un maestro de teología, ni haber sido bautizado, ha actuado toda su vida siguiendo lo que prescribe la razón natural y evitando lo que prohíbe. En este caso, es posible sostener que ese hombre se salvaría de igual modo (ex congruo), como si estuviera bautizado y conociera la doctrina cristiana, ya que sus buenas acciones habrían sido agradables a Dios, y por ello se habría hecho digno de la salvación, la cual no se concluye necesariamente de las buenas obras, sino que depende en último término de la voluntad divina ${ }^{62}$.

De esta manera, la discusión con los filósofos y el lugar de la doctrina revelada toman un sentido distinto. Ya no se trata simplemente de una controversia doctrinal, donde filósofos y teólogos intentan presentar la validez de su posición a expensas de la posición contraria, sino que se destaca el hecho de que dicha oposición es aparente. En efecto, tal como en otros asuntos en disputa, nuestro Doctor busca un punto de encuentro entre ambas posiciones, que permita distinguir con mayor claridad que la diferencia entre ellas es mínima, y que la toma de una u otra posición dependerá en último término de aspectos ajenos a la discusión, como pueden ser la autoridad de la Iglesia o la $\mathrm{fe}^{63}$. Asimismo, en lo que respecta a la salvación del hombre, resulta que no basta con reconocer la verdad de la doctrina que hay que seguir para hacerse digno de la vida eterna, sino que más bien es necesario conducir la propia vida de acuerdo con dicha enseñanza. En este sentido, tanto filósofos como teólogos están de acuerdo sobre el hecho de que el actuar humano debe estar encaminado hacia el bien y que la felicidad se alcanza en presencia de un ser que supera todo lo que se muestra mediante los sentidos. La diferencia, entonces, radicaría en aquello que es propio del cristianismo, a saber, que se trata de un Dios uno y trino, encarnado, creador del mundo, y que llama hacia sí a las criaturas. Eso propio, reconoce el Doctor

\footnotetext{
${ }^{62}$ Duns Scoto, Ordinatio prólogo, n. 55, I 33-34; Guerrero Troncoso, H. "Ley, naturaleza y gracia. Una lectura escotista de la ley natural en santo Tomás", en Casanova Guerra, C. - Serrano del Pozo, I. (eds.) Gratia non tollit naturam sed perficit eam. Sobre las relaciones y límites entre naturaleza y gracia. Actas del II Congreso Internacional de Filosofía Tomista. Universidad Santo Tomás - RIL, Santiago de Chile 2016, pp. 413-440.

${ }^{63}$ Cf., por ejemplo, la discusión sobre el Filioque, Duns Scoto, Ordinatio I, d. 13 n. 1-23, V 1-8; Friedmann, R. L. Intellectual Traditions at the Medieval University. The Use of Philosophical Psychology in Trinitarian Theology among the Franciscans and Dominicans, 1250-1350, Brill, Leiden - Boston 2013, vol. 1, pp. 341-348; Guerrero Troncoso, "Si duo sapientes"; íd., "La questione sul fondamento dell'autorità".
} 
Sutil, puede ser aceptado con ayuda de la fe, ya que no se sigue de una reflexión sobre aquello que se manifiesta cotidianamente, sino que debe ser revelado de alguna manera al hombre.

Y es finalmente esta diferencia la que permite vislumbrar por qué la doctrina de Duns Scoto no se puede considerar como totalmente aristotélica, e incluso, que en cierta medida es una reacción al aristotelismo. Esta reacción no implicaría una refutación o una condena de la filosofía de Aristóteles, sino que se puede interpretar como una superación de aquello que aparece ante un teólogo como insuficiente en un pensamiento que prescinde de la Revelación. En este sentido, los versos de Dante que abren este trabajo, y en particular el contexto en el que aparecen en la Comedia, pueden ilustrar la posición que tenían los teólogos del siglo XIII respecto de una cultura y de una filosofía que no posee un origen cristiano: no obstante su enorme valor, no se puede poner a la misma altura de un pensamiento que reconoce en Dios su principio y su fin, y que considera a la Revelación como una doctrina que guía al hombre para que alcance el conocimiento más perfecto de la esencia y las propiedades divinas que se puede poseer en esta vida ${ }^{64}$.

Resulta entonces que, si bien es innegable que Aristóteles y el aristotelismo constituyen una inspiración para el pensamiento cristiano -y más que una simple inspiración, en lo que respecta a la ontología y a la ética escolásticas-, el principio rector que anima el pensamiento de ambos es en cada caso diverso. Para el Filósofo, el mundo en su multiplicidad es fuente de asombro por sí solo, ya por la inmediatez con la que se manifiesta a la razón humana, pero sobre todo porque es posible remitir todo lo que se hace presente de distintas maneras a un principio uno, en lo cual se recoge todo lo que es, y que él mismo se retira en cuanto que da lugar a que las cosas sean ${ }^{65}$. Para el pensamiento cristiano, en cambio, el mundo alcanza un carácter aún más asombroso en la medida en que nos permite vislumbrar en él a su Creador, esto es, en la medida en que nos permite acercarnos a un ser que supera toda limitación inherente a la naturaleza y que complementa esta última. El modo de acceder a dicho conocimiento, sin embargo, no es inmediato, sino que se halla mediado por la palabra revelada. Así, el pensamiento pagano interpela a la naturaleza, y en dicha interpelación busca dar con los principios que la animan y que configuran su complejo entramado. El pensamiento cristiano, por su parte, se halla interpelado por una palabra que reconoce al mismo tiempo como ajena y como familiar, la voz del Creador, la cual exige al hombre que interprete la realidad que lo circunda y su propia realidad según los términos en los que presenta el mundo, remitido en último

\footnotetext{
${ }^{64}$ Cfr. Dante Alighieri, Commedia. Inferno IV, vv. 31-42, pp. 72-73. Los filósofos están con los héroes en un castillo ubicado en el primer círculo del infierno, cfr. ibíd., vv. 103-147, pp. 77-81.

${ }^{65}$ Queda abierta la discusión si es lícito o no identificar "eso uno", es decir, esa "naturaleza una", a los que alude en el libro IV c. 2 de la Metafísica (1003a 33-34, AL XXV".2 67) con el ipsum esse de los Escolásticos, como hace Heidegger; cfr. Berti, E. Ser y tiempo en Aristóteles, trad. de P. Perkins, Buenos Aires: Biblos, 2011, pp. 13-17.
} 
término a Dios, y conmina al ser humano a que guíe sus acciones según los preceptos que le ha indicado en la Revelación. Dado el carácter limitado y finito del intelecto humano, algunos pensadores cristianos, entre los que se cuenta sin lugar a dudas el beato Juan Duns Scoto, ven en la práctica de la Revelación, es decir, en el hecho de vivir según cuanto ha sido revelado en la Sagrada Escritura, una manera de acercarse a Dios que viene a complementar la sola contemplación.

\section{Referencias Bibliográficas}

\subsection{Fuentes}

Agustín de Hipona (santo), De civitate Dei, ed. B. Dombart - A. Kalb, Corpus Christianorum Series Latina, vol. XLVIII, Brepols, Turnholt 1955.

Aristóteles, Analytica posteriora. Translatio Iacobi, ed. L. Minio-Paluello - B. G. Dod, Aristoteles Latinus, vol. IV ${ }^{1}$, Desclée De Brouwer, Bruges-Paris 1968.

- De anima. Translatio nova Guillelmi de Moerbeka, en: ToMÁs DE AQuino (santo), Sententia libri De anima, en S. Thomae de Aquino Opera omnia, iussu Leonis XIII PM edita, cura et studio Fratrum Praedicatorum, vol. $\mathrm{XLV}^{1}$, Commissio Leonina - Vrin, Roma - Paris 1984.

- De caelo. Translatio Michaelis Scoti, en: Averroes, Commentum magnum super libro De caelo et mundo Aristotelis, ex recognitione F. J. Carmody in lucem edidit R. Arnzen, Peeters, Leuven 2003.

- Ethica Nicomachea. Translatio Roberti Grossaetestae Lincolniensis, "Recensio Pura", ed. R.-A. Gauthier, AL XXVI ${ }^{1-3}$, Brill - Desclée de Brouwer, Leuven - Bruxelles 1972.

- Metaphysica. Recensio et translatio Guillelmi de Moerbeka, ed. G. Vuillemin-Diem, AL XXV ${ }^{3.2}$, Brill, Leiden - New York - Köln 1995.

- Physica. Translatio vetus, ed. F. Bossier - J. Brams, AL VII ${ }^{1}$, Brill, Leiden New York 1990.

Averroes, Commentarium magnum super libros De anima, ed. F. S. Crawford. Corpus Commentariorum Averrois in Aristotelem, Versiones Latinae, vol. VI', The Medieval Academy of America, Cambridge, MA 1953.

Dante Alighieri. Commedia. Inferno. Revisione del testo e commento di Giorgio Inglese, Carocci, Roma 2007.

EnRiQue de Gante, Summa (quaestiones ordinariae), a. 1-5, ed. G. Wilson, Ancient and Medieval Philosophy series 2, vol. XXI, Leuven University Press, Leuven 2005.

- Summae quaestionum ordinariarum, vaenundatur in aedibus Iodoci Badii Ascensii, París 1520. 
Juan Duns Scoto (beato), Ordinatio, en B. Ioannis Duns Scoti Opera omnia, studio et cura Commissionis Scotisticae, vols. I-XIV, Typis Polyglottis Vaticanis, Civitas Vaticana 1950-2013.

- Lectura I, en Opera omnia, vols. XVI-XVII, Typis Polyglottis Vaticanis, Civitas Vaticana 1960-1966.

- Filosofía y teología, Dios y el hombre, traducción del texto latino por B. Aperribay et. al., presentación, introducción y edición de J. A. Merino, Biblioteca de Autores Cristianos, Madrid 2011.

- Prologo dell'Ordinatio, a cura del Seminario Teologico "Immacolata Mediatrice" dei Frati Francescani dell'Immacolata, Casa Mariana Editrice, Frigento 2006

TomÁs de Aquino (santo), Quaestiones disputatae de veritate, en $S$. Thomae de Aquino Opera omnia, iussu Leonis XIII PM edita, cura et studio Fratrum Praedicatorum, vol. XXII, Santa Sabina, Roma 1970-1976.

- Summa contra gentiles I, en Opera omnia, vol. XIII, Garroni, Roma 1918.

- Summa theologiae I, en Opera omnia, vol. IV, Typographia Polyglotta S. C. De Propaganda Fide, Roma 1888.

Weber, R. - Gryson, R. (eds.) Biblia Sacra Vulgata, editio quinta, Deutsche Bibelgesellschaft, Stuttgartt 2005.

\subsection{Estudios}

Aertsen, J.A. - Emery, K. - Speer, A. (eds.) Nach der Verurteilung von 1277: Philosophie und Theologie an der Universität von Paris im letzten Viertel des 13. Jahrhunderts. Studien und Texte. Miscellanea Mediaevalia 28. De Gruyter, Berlin - New York 2001.

Belo, C. "The Concept of 'Nature' in Aristotle, Avicenna and Averroes", en Kriterion (Belo Horizonte) 131 (2015), pp. 45-56.

Berti, E. Ser y tiempo en Aristóteles, traducción de P. Perkins, Biblos, Buenos Aires 2011.

Bowman, L. J. "The Development of the Doctrine of the Agent Intellect in the Franciscan School of the Thirteenth Century", en The Modern Schoolman 50 (1973), pp. 251-279.

Dales, R. C. The Problem of the Rational Soul in the Thirteenth Century, Brill, Leiden - New York - Köln 1995.

Friedmann, R. L. Intellectual Traditions at the Medieval University. The Use of Philosophical Psychology in Trinitarian Theology among the Franciscans and Dominicans, 1250-1350, Brill, Leiden - Boston 2013.

González Ginocchio, D., Ser e infinito en Duns Escoto, Eunsa, Pamplona 2013. 
Guerrero Troncoso, H. "Ley, naturaleza y gracia. Una lectura escotista de la ley natural en santo Tomás", en Casanova Guerra, C. - Serrano del Pozo, I. (eds.) Gratia non tollit naturam sed perficit eam. Sobre las relaciones y límites entre naturaleza y gracia. Actas del II Congreso Internacional de Filosofía Tomista. Universidad Santo Tomás - RIL, Santiago de Chile 2016, pp. 413-440.

- "Los presupuestos metafísicos de la univocidad en Duns Scoto", en Revista Chilena de Estudios Medievales 7 (2015), pp. 11-32.

- $\quad$ "La questione sul fondamento dell'autorità. Duns Scoto e Giovanni Damasceno sulla processione dello Spirito Santo", en Fides Quaerens 3 (2012), pp. 117-151.

- $\quad$ "Si duo sapientes, unius veritatis et non propriae dictionis amatores... Duns Scoto e la dottrina di s. Giovanni Damasceno sulla processione dello Spirito Santo", en Porphyra 131 (2009), pp. 18-39; Porphyra 132 (2009), pp. 34-63. Guzmán Manzano, I. "Naturaleza cognoscitiva de la intelección según Escoto", en Antonianum 49 (1974), pp. 72-96.

Piché, D. La condamnation parisienne de 1277, Vrin, Paris 1999.

PINI, G. Scoto e l'analogia. Logica e metafisica nei commenti aristotelici, Scuola Normale Superiore, Pisa 2002.

- 'Univocity in Scotus' Quaestiones super Metaphysicam. The Solution to a Riddle", en Medioevo 30 (2005), pp. 69-110.

Puig Montada, J. "Averroes y el entendimiento", en Revista Española de Filosofia Medieval 9 (2002), pp. 49-62.

Van Steenberghen, F. Aristotle in the West. The Origins of Latin Aristotelianism, translated by L. Johnston. E. Nauwelarts, Louvain 1955.

WeBer, E.-H. La persone humaine au XIIIe siècle, Vrin, Paris 1991, pp. 287-369.

ZAGAL, H. "On Intellectus Agens and Aristotelian Separate Substances: Aquinas' Waterloo", en Kriterion (Belo Horizonte) 111 (2005), pp. 117-137.

Hernán GuERRERo TronCoso

Universidad Católica del Maule

Talca, Chile

heguerrero@ucm.cl 